\title{
O perfil das empresas inovadoras do Paraná
}

Luiz Alberto Esteves*

RESUMO - O objetivo dessa nota é analisar as características das empresas industriais inovadoras do Paraná. O trabalho também apresenta uma análise comparativa dessas empresas com o conjunto de empresas industriais inovadoras brasileiras. Para este fim, são utilizados os dados da Pesquisa do Ambiente de Investimentos, Brasil 2002, conduzida pelo Banco Mundial.

Palavras- chave: Empresas inovadoras. P\&D. Paraná.

\section{CARACTERÍSTICAS DAS EMPRESAS INOVADORAS}

Antes de iniciar a análise das características das empresas inovadoras, faz-se necessário antecipar algumas definições e esclarecimentos. O primeiro ponto se refere à definição de empresa inovadora. Esse trabalho a define como aquela que declarou na pesquisa ter introduzido alguma inovação de produto ou de processo no período de 2000-2002.

Outro ponto a ser esclarecido é sobre a representatividade da base de dados aqui utilizada. A pesquisa de Ambiente de Investimentos, Brasil 2002, entrevistou 1642 empresas industriais no ano de 2003, sendo que as informações coletadas referiam-se ao exercício do ano anterior, 2002.

A pesquisa utilizou pesos amostrais, o que garantiu a representatividade da amostra para 17.361 estabelecimentos industriais. Contudo, essa pesquisa não é representativa para o conjunto das empresas industriais brasileiras, sendo a mesma enviesada para empresas de grande porte, inovadoras e exportadoras.

Retornando às características das empresas inovadoras, a tabela 1 (em anexo) apresenta as estatísticas descritivas (média e desvio-padrão) das principais variáveis de análise desse trabalho. A primeira coluna lista o conjunto de variáveis, a coluna 2 apresenta os valores médios e desvios-padrão para o conjunto de empresas inovadoras do Paraná, enquanto que a coluna 3 apresenta os mesmos parâmetros estatísticos para as empresas brasileiras (exceto do Paraná).

Uma descrição completa de cada uma das variáveis utilizadas segue no quadro abaixo:

\footnotetext{
* Doutorando em Economia pela Università degli Studi di Siena. É Professor Assistente do Departamento de Economia da Universidade Federal do Paraná. Endereço eletrônico: esteves@ufpr.br.
} 
QUADRO 1 - LISTA DE VARIÁVEIS

\begin{tabular}{|l|l|}
\hline \multicolumn{1}{|c|}{ Variável } & \multicolumn{1}{|c|}{ Descrição } \\
\hline Gastos com P\&D & $\begin{array}{l}\text { Gastos da Empresa em Pesquisa e Desenvolvimento por } \\
\text { trabalhador (Emprego), em R\$ de 2002. }\end{array}$ \\
\hline Treinamento & $\begin{array}{l}\text { Variável Binária (dummy), Treinamento=1 caso a empresa tenha } \\
\text { fornecido treinamento externo a seus funcionários, Treinamento=0, } \\
\text { caso contrário. }\end{array}$ \\
\hline Emprego & $\begin{array}{l}\text { Número médio de empregados, não terceirizados, trabalhando em } \\
\text { período integral no ano de 2002. }\end{array}$ \\
\hline $\begin{array}{l}\text { Intensidade de } \\
\text { Capital }\end{array}$ & $\begin{array}{l}\text { Valor do Estoque de Capital em R\$ de 2002 dividido pelo emprego } \\
\text { do mesmo período. }\end{array}$ \\
\hline Idade da Firma & Idade da firma, em anos. \\
\hline Firma Exportadora & $\begin{array}{l}\text { Variável Binária (dummy), Firma Exportadora=1 caso a empresa } \\
\text { exportou no ano de 2002, Firma Exportadora =0, caso contrário. }\end{array}$ \\
\hline Firma Estrangeira & $\begin{array}{l}\text { Variável Binária (dummy), Firma Estrangeira=1 para a empresa } \\
\text { com mais de 50\% de capital estrangeiro, Firma Estrangeira =0, caso } \\
\text { contrário. }\end{array}$ \\
\hline
\end{tabular}

FONTE: Elaboração própria.

$\mathrm{Na}$ tabela 1, pode-se verificar que as empresas paranaenses investem menos em P\&D do que a média das empresas inovadoras dos outros estados da federação. O gasto médio por empregado destas, no ano de 2002 , foi de $\mathrm{R} \$ 357,87$, enquanto que o gasto médio das empresas inovadoras para o restante do país em 2002 foi de $\mathrm{R} \$ 1027,90$.

Por outro lado, $77 \%$ das empresas inovadoras paranaenses treinaram seus funcionários em universidades, centros de qualificação, pesquisa ou treinamento. Enquanto que essa mesma média é de 59\% para as empresas inovadoras brasileiras (exceto as paranaenses).

As empresas paranaenses também apresentam menores valores de escala (média de 63 trabalhadores, contra 79 para o restante do Brasil), intensidade de capital (média de $\mathrm{R} \$ 1586,70$ contra $\mathrm{R} \$ 4046,48)$ e idade $(12,78$ anos contra 17,05$)$.

As empresas estrangeiras representam 3\% das empresas inovadoras do Paraná, mesmo porcentual observado para o restante do país. Já as empresas exportadoras representam 17\% das empresas inovadoras do Paraná, enquanto que esse porcentual é de $21 \%$ para o restante de empresas inovadoras do Brasil.

\section{A DISTRIBUIÇÃO SETORIAL DE EMPRESAS INOVADORAS}

A tabela 2 (em anexo) apresenta a distribuição setorial das empresas inovadoras. A coluna 1 lista os diferentes setores industriais. As colunas 3 e 4 listam, respectivamente, o número de empresas inovadoras paranaenses em cada setor e seu respectivo porcentual de 
participação. As colunas 4 e 5 reproduzem as informações das colunas 3 e 4 para o restante de empresas inovadoras brasileiras.

As empresas inovadoras paranaenses são fortemente concentradas em três setores: Vestuário/Confecções, Maquinários/Máquinas e Móveis. O conjunto de empresas inovadoras nesses três setores constitui aproximadamente $78 \%$ das empresas inovadoras paranaenses.

O restante das empresas inovadoras brasileiras também é fortemente concentrado em quatro setores: Vestuário/Confecções, Maquinários/Máquinas, Calçados/Artigos de Couro e Móveis. O conjunto de empresas inovadoras nesses três setores constitui aproximadamente $81 \%$ das empresas inovadoras brasileiras (exceto do Paraná).

As diferenças significativas entre as empresas do Paraná e do restante do Brasil são basicamente localizadas em três setores: Calçados/Artigos de Couro, Maquinários/Máquinas e Móveis.

As empresas inovadoras do setor de Calçados/Artigos de Couro representam 4,9\% das empresas inovadoras paranaenses, enquanto que para o restante do Brasil esse porcentual é de 11\%. As empresas inovadoras do setor de Maquinários/Máquinas representam 14,7\% das empresas inovadoras paranaenses, enquanto que para o restante do Brasil esse porcentual é de $19,3 \%$.

O grau de especialização e sofisticação da indústria de madeira e móveis do Paraná pode ser constatado na comparação dos resultados na tabela 2. As empresas inovadoras do setor mobiliário constituem 27,4\% das empresas inovadoras do Paraná, enquanto que para o restante do Brasil esse valor porcentual é exatamente a metade, 13,7\%.

\section{CONSIDERAÇÕES FINAIS}

Foi constatado, ao longo desse trabalho, que as empresas inovadoras do Paraná são fortemente concentradas em três setores industriais: Vestuário/Confecções, Maquinários/Máquinas e Móveis. Também foi verificado um alto grau de especialização do processo industrial inovador do Paraná no setor de Móveis.

Essa distribuição setorial das empresas inovadoras do Paraná pode justificar, em alguma medida, as diferenças na intensidade de capital entre essas empresas e àquelas que compõem o conjunto de firmas inovadoras no restante do país.

Também foi visto que as empresas inovadoras paranaenses investem três vezes menos em Pesquisa e Desenvolvimento do que as empresas inovadoras do restante do país. 
Como a capacidade de inovação das empresas industriais do Paraná não é inferior a média brasileira (esses percentuais são de $88 \%$ e $84 \%{ }^{49}$, respectivamente), pode-se inferir que o esforço inovador no Paraná encontra outros insumos para produção de conhecimento, além dos gastos em P\&D.

A pergunta fundamental nesse ponto é: como as empresas paranaenses conseguem uma taxa de efetividade de inovação igual à média brasileira, investindo três vezes menos em P\&D? O fato de $77 \%$ das empresas inovadoras paranaenses treinarem seus funcionários em universidades, centros de qualificação, pesquisa ou treinamento (contra 59\% par o resto do Brasil) pode fornecer uma pista para a busca dessa resposta.

\section{ANEXOS}

TABELA 1 - ESTATÍSTICAS DESCRITIVAS DAS EMPRESAS DA AMOSTRA

\begin{tabular}{lrr}
\hline & Variável & \multicolumn{1}{c}{ Brasil $^{(3)}$} \\
\hline Gastos com P\&D(2) & 357,87 & 1027,90 \\
& $(1119,75)$ & $(5086,28)$ \\
Treinamento & 0,77 & 0,59 \\
& $(0,42)$ & $(0,49)$ \\
Emprego & 63,74 & 79,00 \\
& $(93,26)$ & $(289,67)$ \\
Intensidade de Capital(2) & 1586,70 & 4046,48 \\
& $(6091,01)$ & $(40240,83)$ \\
Idade da Firma & 12,78 & 17,05 \\
& $(10,43)$ & $(16,69)$ \\
Firmas Exportadoras & 0,17 & 0,21 \\
& $(0,38)$ & $(0,41)$ \\
Firmas Estrangeiras & 0,03 & 0,03 \\
Observações & $(0,18)$ & $(0,18)$ \\
Peso Amostral & 156 & 1196 \\
\hline
\end{tabular}

FONTE: Elaboação própria.

NOTAS: (1) Desvio padrão entre parênteses; (2) Todos os valores monetários são expressos a preços de 2002; (3) As informações das empresas brasileiras excluem as empresas paranaenses.

49 Informação obtida da Pesquisa do Ambiente de Investimentos, Brasil 2002. 
TABELA 2 - DISTRIBUIÇÃO DAS EMPRESAS INOVADORAS

\begin{tabular}{|l|rrrrr|}
\hline \multirow{2}{*}{ Setor } & \multicolumn{2}{|c|}{ Paraná } & \multicolumn{2}{c|}{ Brasi $^{(\mathbf{( 1 )}}$} \\
\cline { 2 - 6 } & Número $^{(2)}$ & \% & Número $^{(2)}$ & \% \\
\hline Alimentos & 61 & 5,1 & 660 & 4,9 \\
Têxtil & 25 & 2,1 & 447 & 3,3 \\
Vestuário/Confecções & 432 & 35,8 & 4904 & 36,5 \\
Calçados/Artigos Couro & 59 & 4,9 & 1483 & 11,0 \\
Produtos Químicos & 43 & 3,6 & 362 & 2,7 \\
Maquinários/Máquinas & 177 & 14,7 & 2586 & 19,3 \\
Produtos Eletrônicos & 31 & 2,6 & 467 & 3,5 \\
Autopeças & 47 & 3,9 & 679 & 5,1 \\
Móveis & 331 & 27,4 & 1834 & 13,7 \\
Total & 1206 & 100 & 13422 & 100 \\
\hline FONTE & \multicolumn{4}{c}{} \\
\hline
\end{tabular}

FONTE: Elaboação própria.

NOTAS: (1) As informações das empresas brasileiras excluem as empresas paranaenses. (2) Números de firmas com peso amostral. 
